
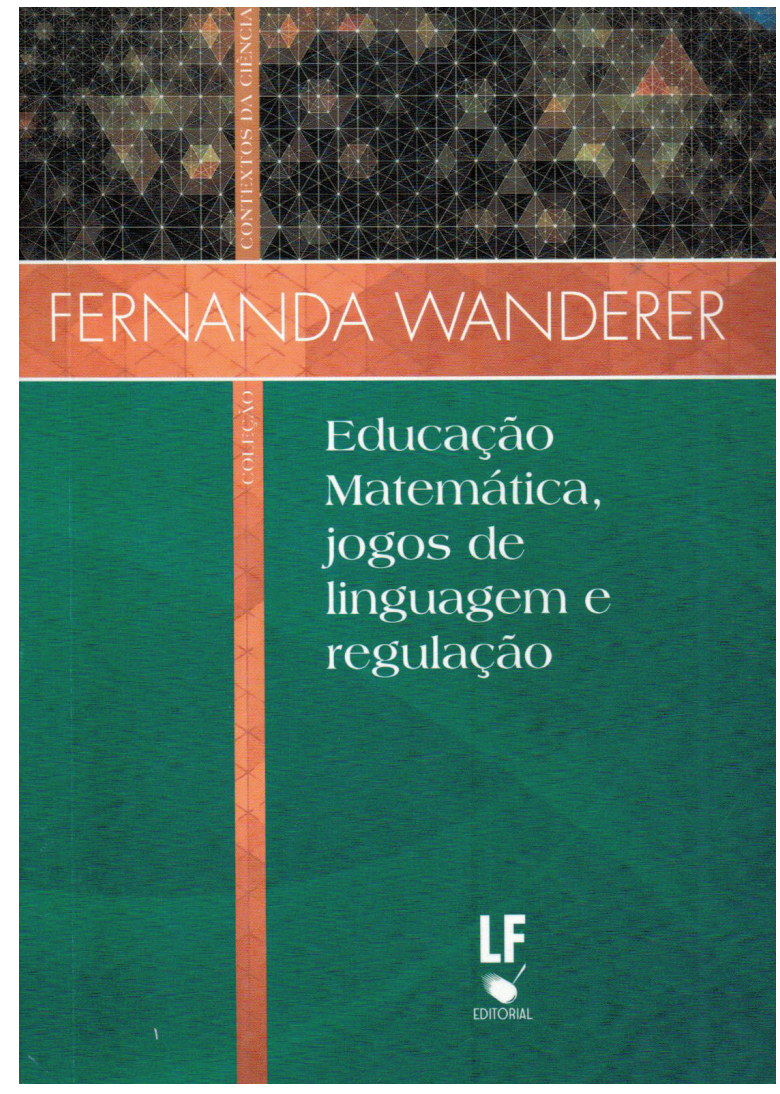

\title{
Resenha Educação matemática, jogos de linguagem e regulação
}

Wanderer, Fernanda. (2014). Educação matemática, jogos de linguagem e regulação. São Paulo: Editora Livraria da Física. (Coleção Contextos da Ciência).

Neila de Toledo e Toledo

O livro Educação matemática, jogos de linguagem e regulação é fruto da tese de doutoramento de Fernanda Wanderer². Assim, reúne, de maneira concisa e não rebuscada, as principais ideias trabalhadas na sua tese, ou seja, os caminhos que percorreu para produzir seu material de pesquisa, a maneira como foi entrelaçando esse material com o referencial teórico escolhido e o modo como construiu sua trama argumentativa.

A pesquisa de Wanderer (2007), que deu origem ao livro, teve como propósito analisar os discursos sobre a escola e sobre a matemática escolar de um grupo de colonos, descendentes de alemães evangélico-luteranos, que frequentavam a escola de Costão (RS), quando da efetivação dos decretos que instituíram a Campanha de Nacionalização, implementada no Brasil no período entre 1937 e 1945 . Para isso, a pesquisadora delimitou como material de pesquisa as narrativas de três mulheres e quatro homens que frequentaram a referida escola no período destacado, cartilhas de matemática - os volumes 1 e 2 da obra Meu livro de contas (1934) - e cadernos de cópia e ditado utilizados naquela instituição. Como aportes teóricos, escolheu algumas noções elaboradas por Michel Foucault e formulações da obra tardia de Ludwig Wittgenstein.

1 Doutoranda em Educação (Unisinos/RS). Professora do IFRS-Campus Sertão (RS). e-mail: neila.toledo@ sertao.ifrs.edu.br.

2 A autora do livro é doutora (2007) e mestre (2001) em Educação pela Unisinos/RS e graduada (1997) em Licenciatura em Matemática pela (UFRGS/RS). Atualmente, é professora permanente do Programa de Pós-Graduação em Educação da UFRGS. A tese de doutorado, que deu origem a essa obra, foi orientada pela professora Drª Gelsa Knijnik, e integra os estudos que vêm sendo desenvolvidos pelo Grupo Interinstitucional de Pesquisa em Educação Matemática e Sociedade (Unisinos). 
Considero pertinente envidenciar que, na pesquisa, a autora refere-se à matemática escolar como aquela que reúne "conhecimentos transmitidos na escola, fruto de um processo de recontextualização da matemática acadêmica (compreendida como os saberes produzidos pelos matemáticos da academia)" (Wanderer, 2014, p.19).

A autora dividiu a obra em quatro partes que têm como objetivo apresentar sua investigação. A primeira parte da obra, intitulada "Abrindo o livro", foi dividida em dois capítulos.

No primeiro capítulo, com base nos estudos realizados na perspectiva foucaultiana, são problematizados alguns discursos produzidos sobre as culturas rurais. Logo no início do capítulo, a autora menciona as razões que a fizeram escolher as culturas rurais, a escola e a matemática escolar como elementos articuladores da pesquisa, e aponta ao leitor como esses três eixos, por meio de marcas historicamente construídas, constituíram-na como uma "mulher branca, descendente de alemães, neta de colonos" (Wanderer, 2014, p.20). Nesse capítulo, a pesquisadora mostra, com clareza, algumas questões vinculadas ao pensamento foucaultiano, as quais sustentaram e produziram as balizas teóricas do seu estudo. Dentre elas, encontra-se a discussão do poder como "produtivo, disperso e vinculado ao saber" (Wanderer, 2014, p.32).

O segundo capítulo tem como foco apresentar o campo empírico do estudo, para isso, a pesquisadora faz um detalhamento minucioso de alguns aspectos sobre a produção do material de pesquisa, por exemplo: como chegou até as cartilhas de matemática e aos cadernos de cópia e ditado utilizados na escola naquele período; como se deu a aproximação inicial com os participantes da pesquisa; qual foi o tempo de duração das entrevistas narrativas, etc. Ou seja, a autora mostra os caminhos percorridos até a definição dos discursos sobre a escola e sobre a matemática escolar de um grupo de colonos como objeto de estudo. Nesse trecho da obra, a autora faz uso, pela primeira vez, de alguns excertos retirados do seu material de pesquisa, com o intuito de expor como, em muitos momentos, a pesquisadora conduziu-se e foi sendo conduzida na interação com os participantes.

Na parte 2, "Escola, regulação e disciplinamento", a pesquisadora aborda as tecnologias de poder postas em ação sobre os descendentes de alemães do estado do Rio Grande do Sul, que tinham como objetivo a "gestão da população" e o "[...] disciplinamento de seus corpos no período da efetivação dos decretos que instituíram a Campanha de Nacionalização" (Wanderer, 2014, p.64). A pesquisadora dividiu essa parte em dois capítulos.

No primeiro capítulo, a autora analisa os mecanismos de regulação da população, particularmente dos descendentes de alemães, no decorrer da Campanha de Nacionalização. Por meio da análise de alguns excertos que compõem o material 
de pesquisa, destaca que, juntamente com os mecanismos que foram postos em funcionamento com vistas à regulação da população alemã no período da Campanha de Nacionalização, também agia uma tecnologia de poder sobre os corpos dos escolares, "disciplinando-os, sujeitando-os, constituindo-os como sujeitos de um modo específico" (Wanderer, 2014, p. 116).

O segundo capítulo examina as técnicas disciplinares postas em funcionamento sobre os corpos dos escolares do referido grupo naquele período, isto é, a autora analisa o poder disciplinar e o uso que faz de seus três instrumentos: vigilância hierárquica, sanção normalizadora e exame. Para tal, Wanderer dividiu o capítulo em três seções, apontando que, por meio das técnicas como vigilância, controle, exercício, inspeção e exame, os sujeitos são moldados e suas condutas são afetadas para que se tornem “pessoas de um determinado modo” (Wanderer, 2014, p. 172).

A terceira parte da obra, intitulada "Etnomatemática, jogos de linguagem e regulação", foi dividida pela autora em três capítulos, os quais têm como finalidade mostrar que a matemática escolar também atuava como mecanismo de regulação dos escolares. Assim, esse capítulo trata de problematizar a matemática escolar presente na escola de Costão no tempo estudado pela pesquisadora.

No primeiro capítulo, Wanderer (2014) elenca alguns elementos das teorizações pós-estruturalistas, em sua vertente relacionada ao pensamento foucaultiano. Dentre eles, encontra-se "a ideia de progresso constante, razão universal, verdades absolutas, sujeito dotado de uma racionalidade objetiva” (p. 175), além de outras que respaldam o projeto moderno para a sociedade, para a educação e, em particular, para a educação matemática. A autora, servindo-se dessas teorizações, problematiza também o campo da Etnomatemática, “caixa de ferramentas” escolhida para analisar a matemática escolar posta em ação na escola de Costão, no período da Campanha de Nacionalização (p 175). Cabe aqui destacar que a autora faz uma reflexão, em seu trabalho, sobre a perspectiva Etnomatemática, orientando-a em uma direção filosófica.

O capítulo 2 amplia as discussões do campo etnomatemático, destacando noções do pensamento de Wittgenstein, presentes em sua obra Investigações Filosóficas, publicada em 1953. Nesse âmbito, por intermédio do exercício analítico do material de pesquisa sustentado pelas teorizações etnomatemáticas, apoiadas na obra tardia do filósofo Wittgenstein, a autora conclui que a matemática escolar, produzida na escola estudada, foi sendo constituída como um "conjunto de jogos de linguagem marcados pela escrita, pelo formalismo, pela 'pureza', apoiado em fundamentos como a tabuada [ênfase do autor]" (Wanderer, 2014, p.222). Ainda nesse capítulo, conclui que as matemáticas geradas nas práticas cotidianas dos participantes da pesquisa fazem uso de uma "gramática diferente daquela que engendra a matemá- 
tica escolar" (p.222). Com base na análise das narrativas e no texto elaborado por um dos sujeitos da pesquisa, a autora evidencia que o fato de a matemática escolar de Costão possuir uma gramática com regras, que enfatizam a importância de decorar a tabuada, e efetuar operações que seguem um padrão, engendra critérios de racionalidade específicos.

No último capítulo da parte três, o foco principal da autora, seguindo o exame do material de pesquisa, foi desenvolver o argumento de que a matemática escolar produzida naquela instituição, no período destacado, colocava em ação mecanismos de regulação de sujeitos escolares pela imposição da língua portuguesa por meio de atividades pedagógicas e da própria estrutura do conhecimento matemático. Segundo a autora, está evidente, nas narrativas dos participantes da pesquisa, que a proibição da língua alemã na escola ocasionava mudanças não só na maneira de se comunicar, como também na racionalidade engendrada pela matemática.

Ainda nesse capítulo, a autora destaca que a matemática escolar foi sendo significada como um campo marcado por linearidade, hierarquia e ordem. Isso se mostra evidenciado nas maneiras específicas de efetuar operações matemáticas e na resolução de problemas, os quais se baseavam no uso de algoritmos escritos, de tabuada e de algumas decomposições. Com base nisso, ressalta que a matemática escolar, ao sustentar-se por práticas de repetição e memorização, estabelecia uma racionalidade específica que agia como mecanismo de regulação do pensamento dos alunos e dos professores.

A fim de mostrar a importância do estudo sobre a educação matemática nas escolas de imigração alemã brasileiras no período da Campanha de Nacionalização do Brasil, ressalto que já foram produzidos, além da tese de Wanderer (2007), outros trabalhos, como os de: Eisseler (2012), Gaertner (2004) e Mauro (2005).

Sobre as pesquisas destacadas no parágrafo anterior, dois pontos relacionados ao ensino e ao aprendizado da matemática nas escolas étnicas alemãs foram evidenciados, um referente ao uso do cálculo denominado "mental" como estratégia para a resolução dos exercícios propostos e a preocupação com a aplicação prática dos conteúdos, como por exemplo, no que diz respeito ao cálculo com os sistemas de medida. Assim, pelo apresentado aqui, a investigação de Wanderer (2007) percorre um caminho distinto e apresenta novos elementos de análise sobre a educação matemática no contexto das formas de vida de regiões da imigração alemã do Rio Grande do Sul.

Na última parte do livro, intitulado "Fechando o livro...", a autora apresenta algumas considerações sobre a investigação desenvolvida e evidencia que sua pretensão não foi realizar uma conclusão definitiva da pesquisa, mas apenas retomar alguns aspectos que pudessem dizer mais sobre o trabalho realizado. Finaliza o capítulo, 
salientando que o exercício analítico proposto na obra produziu "verdades", mas considera que outras tantas também poderiam ter sido produzidas - e não descarta que, no futuro, tantas outras poderão surgir, visto que é possível continuar pensando e estudando sobre a escola de Costão no período da Campanha de Nacionalização, investigando outros significados para o material de pesquisa.

A presente obra contribui sobremaneira para o campo da Etnomatemática e para a área da Educação Matemática, configurando-se em uma leitura interessante para aqueles que se dedicam à pesquisa, ou que têm intenção de iniciar uma investigação nessa área de conhecimento. No decorrer do livro, a autora mostra, de maneira detalhada, cuidadosa e comprometida, como foi tecendo as tramas de sua pesquisa, os movimentos realizados na composição do terreno investigativo, os caminhos que a levaram a desenvolver o estudo, e como foi conformando o campo empírico e os aportes teóricos que sustentam a investigação. Outro aspecto a ser salientado é que a pesquisadora demonstra, no exercício analítico empreendido, que opera com rigor com as ferramentas teóricas, engendrando uma rede argumentativa que possibilita responder às questões que conduziam o estudo. Assim, aponta a relevância e o potencial da investigação desenvolvida.

\section{Referências}

Eissler, J. R. (2012). Contribuições da escola teuto-brasileira ao ensino de matemática nos anos iniciais do Ensino Fundamental. Dissertação de Mestrado profissionalizante em Ensino de Ciências Naturais e Matemática. Blumenau: Fundação Universidade Regional de Blumenau.

Gaertner, R. (2004). A matemática escolar em Blumenau (SC) no período de 1889 a 1968: da Neue Deutsche Schule à Fundação Universidade Regional de Blumenau. Tese de Doutorado em Educação Matemática. Rio Claro: Universidade Estadual Paulista.

Mauro, S. (2005). Uma história da matemática escolar desenvolvida por comunidades de origem alemã no Rio Grande do Sul no final do século XIX e início do século XX. Tese de Doutorado em Educação Matemática. Rio Claro: Universidade Estadual Paulista.

Wanderer, F. (2007). Escola e matemática escolar: mecanismos de regulação sobre sujeitos escolares de uma localidade rural de colonização alemã do Rio Grande do Sul. Tese de Doutorado em Educação. São Leopoldo: Universidade do Vale do Rio dos Sinos.

Recebido em: 03/09/2015

Aprovado em: 19/11/2015 